\title{
ALTAS HABILIDADES/SUPERDOTAÇÃO NA FORMAÇÃO DE PROFESSORES BRASILEIROS E PORTUGUESES: UM ESTUDO COMPARATIVO ENTRE OS CASOS DA UNESP E DA UMINHO
}

\author{
BÁRBARA AMARAL MARTINS ${ }^{1}$ \\ ORCID: https://orcid.org/0000-0003-4278-1661 \\ MIGUEL CLAUDIO MORIEL CHACON ${ }^{2}$ \\ ORCID: https://orcid.org/0000-0002-6473-8958 \\ LEANDRO DA SILVA ALMEIDA ${ }^{3}$ \\ ORCID: https://orcid.org/0000-0002-0651-7014
}

\begin{abstract}
RESUMO: Considerando-se a importância dos professores na identificação e estímulo dos estudantes com altas habilidades/superdotação (AH/SD), propomos investigar e comparar a estrutura e possibilidades da formação docente sobre esta temática no curso de Pedagogia da UNESP, Campus de Marília, no Brasil e o curso de Licenciatura em Educação Básica acrescido dos Mestrados em Ensino da UMinho, Campus de Gualtar, em Portugal. Os objetivos específicos são: investigar o conhecimento dos estudantes sobre AH/SD; analisar a relação de projetos de pesquisa e extensão com a formação de professores; verificar o acervo de produções sobre AH/SD dos campi. Os dados foram coletados por meio de entrevistas e consulta às bases de documentação. A produção e aquisição de materiais bibliográficos, a maneira como o assunto é abordado nas disciplinas e a possibilidade de participar de projetos de pesquisa e extensão tem relação direta com o envolvimento científico dos docentes dos cursos com as $\mathrm{AH} / \mathrm{SD}$.
\end{abstract}

Palavras-chave: Educação especial, formação docente, altas habilidades, superdotação.

\section{HIGH ABILITIES/GIFTEDNESS IN THE EDUCATION OF BRAZILIAN AND PORTUGUESE TEACHERS: A COMPARATIVE STUDY BETWEEN THE CASES OF UNESP AND UMINHO}

\begin{abstract}
Considering the teachers importance in the identification and encouragement of students with high abilities/giftedness, we propose to investigate and compare the structure and possibilities of teacher education on the topic in the Pedagogy course of UNESP, Marilia Campus, in Brazil and in the Education Basic bachelor course and Masters in Teaching at UMinho, Gualtar Campus, in Portugal. The specific objectives are: to investigate students' knowledge about high abilities/giftedness; to analyze the relationship of research and extension projects with teacher education; to verify the productions

\footnotetext{
${ }^{1}$ Universidade Federal de Mato Grosso do Sul (UFMS), Corumbá, MS, Brasil. < barbara.martins@ufms.br>

2 Universidade Estadual Paulista "Júlio de Mesquita Filho" (Unesp) Marília, SP, Brasil. <miguelchacon@marilia.unesp.br>

${ }^{3}$ Universidade do Minho (UMinho), Braga, Portugual.<leandro@ie.uminho.pt> 
collection on high abilities/giftedness in the campuses. The data were collected through interviews and consultation of the documentation bases. The production and acquisition of bibliographic materials, the way the topic is approached in the disciplines and the possibility of participating in research and extension projects are directly related to the scientific involvement of the teachers of the courses with the high abilities/giftedness.

Keywords: Special education. Teacher education. High abilities. Giftedness.

\section{ALTAS CAPACIDADES/SUPERDOTACIÓN EN LA FORMACIÓN DE PROFESORES BRASILEÑOS Y PORTUGUÉS: UN ESTUDIO COMPARATIVO ENTRE LOS CASOS DE UNESP Y UMINHO}

RESÚMEN: Teniendo en cuenta la importancia de los docentes para identificar y estimular a los estudiantes superdotados, proponemos investigar y comparar la estructura y las posibilidades de formación de docentes sobre este tema en el curso de Pedagogía en la UNESP, Campus de Marília, en Brasil, y el Grado en Educación Básica más el Máster en Enseñanza de UMinho, Campus de Gualtar, en Portugal. Los objetivos específicos son: investigar el conocimiento de los estudiantes sobre la superdotación; analizar la relación entre proyectos de investigación y extensión con la formación docente; verifique la colección de producciones sobre la superdotación de los campus. Los datos fueron recolectados a través de entrevistas y consultas con las bases de documentación. La producción y adquisición de materiales bibliográficos, la forma en que se aborda el tema en las disciplinas y la posibilidad de participar en proyectos de investigación y extensión están directamente relacionado con la participación científica de los profesores de los cursos con la superdotación.

Palabras clave: Educación especial, formación docente, altas capacidades, superdotación.

\section{INTRODUÇÃO}

A temática das altas habilidades/superdotação despertou pouco interesse por parte dos pesquisadores e da sociedade, de um modo geral, durante um longo período. Nos últimos anos, tem recebido maior visibilidade (IORO; CHAVES; ANACHE, 2016), porém, a realidade escolar ainda encontra-se permeada pela falta de atenção adequada às necessidades dos estudantes com capacidades mais elevadas, os quais nem sempre são identificados nos contextos escolares do Brasil e de Portugal (ALENCAR; FLEITH, 2005; BARRETO; METTRAU, 2011; FLEITH et al, 2010).

Muitos acreditam que o estudante com AH/SD já foi beneficiado por sua capacidade de aprendizagem avançada e não necessita de atenção especial (PORTER, 2005). Essa crença sustenta-se na supervalorização dos aspectos genéticos, em detrimento das influências do ambiente, isto é, percebe-se o estudante como um indivíduo privilegiado por capacidades superiores inatas e julga-se injusto lhe oferecer alguma atenção educacional distinta das que recebem os demais (ALENCAR; FLEITH, 2005). No entanto, aqueles que advogam em favor de ensino diferenciado para os alunos com AH/SD, não estão defendendo o favorecimento de alguns, mas a educação adequada às peculiaridades de cada criança (PORTER, 2005), independentemente de estar acima ou abaixo da média.

Ademais, os estudantes com $\mathrm{AH} / \mathrm{SD}$ requerem atividades que envolvam pesquisa e pensamento criativo, atrelados ao aprofundamento de conhecimentos. Ações que, no trabalho em sala de aula comum, podem ser estendidas a todos os alunos (RENZULLI, 2014), contribuindo "para o 
crescimento acadêmico, motivacional e criativo do grupo de pertencimento do estudante" (BARRETO; METTRAU, 2011, p. 424). As autoras acrescentam que "investir em ações educativas para as pessoas com altas habilidades, é implementar educação de qualidade e desenvolvimento para todos no seu entorno" (p. 424).

Obviamente, estes estudantes podem demandar outras ações além do enriquecimento curricular, como, por exemplo, o enriquecimento extracurricular, o agrupamento, a aceleração ou a combinação destas respostas educativas (ANTUNES; ALMEIDA, 2009; MARTINS, 2015). Negar a atenção educacional a esse tipo de aluno é ignorar o direito de satisfação as suas necessidades educacionais especiais, porém, enquanto no Brasil esses estudantes são considerados pertencentes ao público-alvo da Educação Especial, em Portugal, o Decreto-Lei no 3/2008, que dispõe sobre os apoios especializados, não faz qualquer menção a esse alunado (BRASIL, 1996; PORTUGAL, 2008).

Apesar desse avanço da legislação brasileira em relação à portuguesa, ambos os países apresentam uma realidade educacional distante do esperado no que tange ao incentivo para o desenvolvimento das AH/SD (ANTUNES; ALMEIDA, 2009; BAHIENSE; ROSSETTI, 2014; BARRETO; METTRAU, 2011; CARVALHO, 2016; CASTELLÓ; MARTINEZ, 1999; FORTES; FREITAS, 2007; MARTINS; ALENCAR, 2011; MIRANDA; ALMEIDA, 2003; PÉREZ; FREITAS, 2011). Parte da falta de atenção às necessidades dos estudantes com AH/SD está relacionada ao desconhecimento dos educadores a respeito de tal fenômeno, evidenciando uma lacuna na formação docente, a qual tem implicações no reconhecimento e ensino desses discentes. Segundo Román Sánchez, Gallego Rico e Alonso (1996), o êxito das medidas educacionais para alunos com AH/SD está fortemente relacionado à formação dos docentes, pois quando desprovidos de qualquer preparação, tendem a demonstrar desinteresse e hostilidade com esses estudantes. Assim, "Os futuros professores deveriam contar com uma formação especial que lhes permitiria satisfazer de forma adequada às necessidades das crianças com talento, superdotadas e criativas” (p. 354, tradução nossa).

Em uma investigação sobre as representações de professores a respeito de estudantes com AH/SD, Barreto e Mettrau (2011) obtiveram informações, por meio de questionários, junto a 36 professores do $1^{\circ}$ ano do ensino fundamental ao $3^{\circ}$ ano do ensino médio de uma escola pública federal, localizada no estado do Rio de Janeiro, Brasil. Esses professores apresentavam um nível de formação máxima que variava de ensino superior completo (4) a doutoramento concluído (3), sendo que a maioria (14) possuía curso de especialização. O grupo foi unânime em afirmar já ter ouvido falar sobre AH/SD, porém, apenas dois relataram ter adquirido conhecimentos sobre essa temática por meio de formação sistematizada (formação inicial, continuada, capacitações). O restante tomou conhecimento desta especificidade por meio da mídia ou conversas formais e informais no âmbito profissional, havendo ainda, um caso de vivência familiar. Somente $19 \%$ consideraram-se aptos a trabalhar com essa clientela e $89 \%$ acreditavam que o professor é o profissional mais qualificado da escola para identificar e atuar com esse público. Revelaram ter recebido estudantes oriundos de outras instituições, que apresentavam registro de $\mathrm{AH} / \mathrm{SD}$ em seus históricos escolares, porém, não foram tomadas medidas em relação à continuidade do processo de investigação do diagnóstico ou implementação de ações educativas, embora 63\% dos participantes alegassem ter ciência do direito desses estudantes ao atendimento educacional especializado. Todos manifestaram o desejo de saber mais sobre o assunto (BARRETO; METTRAU, 2011).

Em estudo sobre a formação de professores a respeito das AH/SD em Portugal, Matos (2015) investigou 103 professores do pré-escolar ao secundário, por meio de questionários. Destes, 75 atuavam em escolas no momento da pesquisa, estando os demais divididos em: estudantes (12), atuantes em área diversa à educacional (13), desempregados (3). A maioria dos participantes tinha apenas o curso de licenciatura (61), sendo que 12 ainda estavam cursando-o e, no nível mais elevado de formação, havia dois participantes com doutorado. Do total de 103 professores, 31 afirmaram que o tema foi abordado durante a formação inicial enquanto 12 tiveram contato com essa temática na formação continuada. Ainda assim, 93 participantes não se consideravam preparados para trabalhar com alunos com AH/SD e quando questionados se esses estudantes integram o grupo dos alunos com necessidades educacionais especiais, 38 responderam que sim, 45 responderam que não e 20 não souberam responder. Apresentaram 
ideias equivocadas, como a crença de que esses estudantes são emocional e socialmente desajustados (91), mas, em sua maioria, não sentem necessidades de formação nessa área (78).

O desinteresse dos professores pelo assunto pode ser justificado pela própria falta de conhecimentos, pois, com base no senso comum, cultivam-se mitos e estereótipos (PÉREZ, 2003).

A Rede de Informação sobre Educação na Europa - Eurydice (2008, p. 19) reconhece a importância dos professores no processo de identificação, apoio e acompanhamento das ações educacionais voltadas a esse público e ressalta que, independentemente das diretrizes adotadas pelos países para o incentivo às $\mathrm{AH} / \mathrm{SD}$ "importa examinar a forma como os professores são formados para trabalharem diariamente com jovens que evidenciem capacidades e potencial excepcionais".

Este estudo tem por objetivo investigar e comparar a estrutura e as possibilidades de formação de professores acerca das altas habilidades/superdotação em duas universidades públicas: a Universidade Estadual Paulista "Júlio de Mesquita Filho" (UNESP), no Brasil e a Universidade do Minho (UMinho), em Portugal. Para tal investigação, estabelecemos um recorte de modo a analisar um campus de cada universidade: UNESP, Campus de Marília e UMinho, Campus de Gualtar, ambos com pesquisa e produção científica nessa área. Focalizou-se o processo de formação de professores para o ensino de crianças de 3 a $10 \operatorname{anos}^{4}$ de idade em cada campus. No Brasil, essa formação acontece no curso de graduação em Pedagogia e em Portugal, se dá por meio da Licenciatura em Ensino Básico acrescida de mestrado em ensino ${ }^{5}$.

Como objetivos específicos, propomos: (i) Investigar o conhecimento dos estudantes acerca da temática altas habilidades/superdotação em curso de formação inicial para professores; (ii) Analisar a relação de projetos de pesquisa e extensão com a formação dos estudantes; (iii) Verificar o acervo de produções sobre altas habilidades/superdotação que as universidades disponibilizam aos seus estudantes.

\section{MÉTODO}

Tendo encontrado, anteriormente, evidências de que as AH/SD estão entre os conteúdos integrantes dos Planos de Ensino de disciplinas dos cursos analisados (MARTINS; CHACON; ALMEIDA, 2018), objetivamos investigar o conhecimento dos estudantes sobre esse assunto. Para isso, entrevistamos seis estudantes, sendo três da UNESP e três da UMinho, todas do sexo feminino, cujas idades variavam de 21 a 25 anos. As participantes tinham concluído a formação inicial durante o primeiro semestre de 2017 ou estavam cursando o último período. Os nomes usados para diferenciá-las são fictícios.

Objetivando analisar a relação entre projetos de pesquisa e extensão com a formação dos estudantes, primeiramente acessamos os currículos dos docentes dos cursos investigados. Com base no levantamento dos projetos relacionados às $\mathrm{AH} / \mathrm{SD}$, entrevistamos os professores com investigação na área, a fim de verificar a participação dos acadêmicos nessas atividades e suas contribuições em termos de produção científica e apoio à comunidade externa. Os professores serão identificados como Professor A (UMinho) e Professor B (UNESP).

O Professor A envolveu-se com a área das AH/SD a partir do ano de 1987, quando foi fundada a Associação Portuguesa de Crianças Sobredotadas (APCS), na qual participou de reuniões e atuou na recepção e acolhimento de convidados vindos do exterior, especialmente dos Estados Unidos (World Council for Gifted and Talented Children) e do Brasil. Esses pesquisadores internacionais iam para a cidade do Porto participar dos congressos então organizados e ministrar formações. A partir do contato com essas pessoas, o Professor A veio a conhecer a temática, nunca abordada em sua formação de psicólogo, tomando conhecimento sobre a sua representatividade em outros países e despertando o seu interesse. No ano de 1998, participou da fundação da Associação Nacional de Estudo e Intervenção na Sobredotação (ANEIS) junto a outros psicólogos, professores e estudantes e tem ocupado cargos de direção desde o início até a atualidade.

\footnotetext{
${ }^{4}$ Essa delimitação da faixa etária se deve ao fato de que, enquanto no Brasil, a Educação Infantil destina-se a crianças de 0 a 5 anos, em Portugal, a Educação Pré-Escolar ocorre dos 3 aos 5 anos da criança.

${ }^{5}$ Dada a adesão de Portugal ao Processo de Bolonha, o mestrado em ensino é pré-requisito para o exercício do magistério, isto é, integra a formação inicial de professores.
} 
O Professor B iniciou seu envolvimento com a temática no ano de 2009 em decorrência da extinção das habilitações do curso de Pedagogia, ocasionada pela publicação da Resolução CNE/CP N ${ }^{\circ}$ 1, de 15 de maio de 2006, que institui as Diretrizes Curriculares Nacionais para o referido curso, (BRASIL, 2006). Anteriormente, o Professor B dedicava-se, em especial, aos estudos da deficiência física, porém, o Campus já dispunha de outros três docentes envolvidos com tal temática, ao passo que as altas habilidades/superdotação representavam um campo de investigação até então descoberto, pois não despertava o interesse dos demais professores integrantes do departamento de educação especial da unidade. Logo que iniciou seus estudos e pesquisas em AH/SD, passou a desenvolver ações de identificação e intervenção junto a crianças de escolas do município, beneficiando assim, a comunidade externa.

Com relação ao acervo de produções científicas sobre AH/SD disponíveis nas universidades, um levantamento foi realizado no mês de julho de 2017. Inicialmente, consultaram-se as bases de documentação disponíveis on line, a partir dos descritores: giftedness; high ability; sobredotação; superdotação; dotação; talento; altas habilidades/superdotação; altas habilidades; altas capacidades; precocidade. Foram considerados somente os periódicos e livros físicos adquiridos pelas unidades analisadas, bem como as teses, dissertações, trabalhos de conclusão de curso e artigos produzidos pelos docentes e estudantes dos campi investigados.

Para ter acesso aos materiais disponíveis na UNESP - Campus de Marília, acessamos o Catálogo Athenas, que reúne livros, teses, dissertações e trabalhos de conclusão de curso de todas as unidades da UNESP; consultamos também o Portal de Revistas Eletrônicas - FFC - UNESP Marília, que congrega 19 periódicos publicados por este Campus; além do Repositório Institucional UNESP, que visa a armazenar e disseminar as produções da universidade no formato de artigos, livros, capítulos de livros, teses, dissertações e outros. Observa-se que foram desconsideradas as produções científicas presentes em outros campi, embora haja a possibilidade de empréstimo entre as diversas bibliotecas da universidade e ainda, junto à Universidade de São Paulo (USP) e a Universidade de Campinas (UNICAMP).

A consulta aos materiais disponíveis na UMinho se deu a partir do Catálogo, onde são encontrados livros, teses, dissertações e outros; bem como por meio do RepositóUM que reúne as publicações produzidas no âmbito da universidade, de modo a divulgar os artigos, livros, capítulos de livros, teses, dissertações e outros, de autoria/orientação de seus docentes. Porém, ressalta-se que em consulta presencial às estantes das bibliotecas, constatou-se que muitos dos livros da UMinho (24) não foram localizados na busca digital. Dessa maneira, os catalogamos também presencialmente.

No tocante à análise dos dados, as entrevistas foram integralmente transcritas e submetidas à análise de conteúdo (BARDIN, 2016). A análise das entrevistas com os estudantes revelou as categorias: (a) As altas habilidades/superdotação nos currículos, com as subcategorias (i) Conteúdos disciplinares e (ii) Outras fontes de informação e (b) Conhecimentos adquiridos, com as subcategorias (iii) Concepção de altas habilidades/superdotação; (iv) Características de estudantes com altas habilidades/superdotação; (v) Processo de identificação. Duas categorias emergiram da análise das entrevistas com os docentes: (c) Contribuições teóricas e (d) Contribuições práticas. O acervo bibliográfico foi quantitativamente analisado.

\section{RESULTADOS}

Os resultados estão organizados em três seções. A primeira refere-se às AH/SD no contexto das disciplinas oferecidas e envolve análise documental, bem como opiniões de estudantes; a segunda aborda as contribuições dos projetos de pesquisa e extensão para a formação docente em AH/SD, a partir de relatos dos professores universitários e a terceira trata das produções científicas acerca da temática que se encontram disponíveis nas unidades investigadas. 


\section{As altas habilidades/superdotação enquanto componente curricular}

Freitas e Stobäus (2011) compreendem que o currículo é um espaço que congrega saber e poder, envolvendo "todas as ações que fazem parte do cotidiano educacional e do fazer pedagógico na escola" (p. 497). Os autores esclarecem que a etimologia da palavra currículo nos remete ao termo latino scurrere, que carrega o sentido de prescrição.

Nessa perspectiva, realizamos uma investigação preliminar analisando os conteúdos trabalhados nas disciplinas dos cursos em estudo, o que nos remeteu aos Planos de Ensino. Durante essa etapa, encontraram-se indícios de que a temática das AH/SD está presente na formação de professores no curso de Pedagogia da UNESP (Campus de Marília), especificamente na disciplina Currículo $e$ Necessidades Educacionais Especiais e nos cursos de mestrado em ensino da UMinho (Campus de Gualtar), nomeadamente na unidade curricular Inclusão e Necessidades Educativas Especiais (MARTINS; CHACON; ALMEIDA, 2018).

Ao investigarmos os conhecimentos dos futuros professores sobre a temática das AH/SD, pudemos confirmar as evidências de que os conteúdos sobre AH/SD integram os currículos dos cursos analisados, bem como inferir sobre a eficácia do trabalho formativo desenvolvido, a partir da identificação de duas categorias: (a) As altas habilidades/superdotação nos currículos e (b) Conhecimentos adquiridos:

\section{a) As altas habilidades/superdotação nos curriculos}

Ambos os campi investigados têm as AH/SD como um componente curricular presente tanto como (i) conteúdo disciplinar quanto em (ii) outras fontes de informação.

\section{Conteúdo disciplinar}

Em estudo anterior (MARTINS; CHACON; ALMEIDA, 2018), não encontramos as AH/SD explicitadas enquanto conteúdo dos planos de ensino das disciplinas que integram o curso de Pedagogia da UNESP (Campus de Marília). No entanto, a presença de referências bibliográficas básicas que abordam, entre outros, este tema, serviu-nos de evidência do estudo das AH/SD na disciplina Curriculo e Necessidades Educacionais Especiais, o que não se confirmou nas entrevistas. Embora seja um conteúdo presente na formação, não houve consenso a respeito da disciplina em que esse estudo ocorre, apenas a associação dele ao Professor B: "Acredito ser na disciplina Diversidade, Diferença e Deficiência [...] ministrada pelo [Professor B]" (Juliana, UNESP, 2017); "Foi ministrada pelo [Professor B] [...] eu lembro que o nome da disciplina deixava claro que era sobre isso, mas eu não me lembro exatamente como era" (Mônica, UNESP, 2017); “Sim, [em] Desenho universal” (Larissa, UNESP, 2017).

Durante a entrevista com o Professor B, este nos esclareceu que já ministrou a disciplina Diversidade, Diferença e Deficiência, estando responsável atualmente, por Desenho universal, Acessibilidade e Adaptações. O docente aborda a temática das AH/SD em todas as disciplinas que ministra, mesmo que não configure um conteúdo previamente estabelecido, pois compreende que, uma vez que os alunos com $\mathrm{AH} / \mathrm{SD}$ pertencem ao público-alvo da educação especial, suas características e necessidades devem ser contempladas nos estudos desta área.

As estudantes da UNESP relataram que os principais assuntos abordados no âmbito das AH/SD foram: inclusão; conceitos de superdotação; características de alunos com AH/SD e mitos.

A partir dos relatos das estudantes da UMinho, constatou-se unanimemente que a sobredotação não está entre os temas estudados durante a Licenciatura em Ensino Básico: "Nunca se falou sobre a sobredotação na licenciatura" (Manuela, UMinho, 2017). "Não, pelo que me lembro, acho que nunca trabalhamos essa temática" (Carmen, UMinho, 2017). "Não, na licenciatura não" (Sílvia, UMinho, 2017).

Durante o mestrado, o assunto é mencionado na unidade curricular Necessidades Educativas Especiais, porém, parece-nos que bastante superficialmente:

"Também não. Se foi, eu não me estou a lembrar, mas se foi, foi algo muito, muito passageiro" (Carmen, UMinho, 2017). "Foi falado, mas de forma superficial” (Sílvia, UMinho, 2017).

Sim, foi abordado, muito pouco, [...] abordamos mais dificuldade de visão, dificuldades auditivas, o que se falou sobre sobredotação foi muito superficial, nem chegaram a ser conteúdos de testes. [...] juntamente nós temos manual, [...] lá um dos tópicos desse manual era a sobredotação só que como o tempo é escasso, as professoras de certo, optaram por abordar esses temas que eu 
mencionei em vez da sobredotação, mas deveria ser um conteúdo que deveria ser abordado obviamente (Manuela, UMinho, 2017).

Em relação aos assuntos tratados durante as aulas, duas estudantes não se recordaram, enquanto uma delas reforçou a superficialidade do estudo: "[a sobredotação] apenas foi falada na sua definição de forma superficial, e mencionada como um tópico a abordar, e nada mais" (Manuela, UMinho, 2017).

A partir da análise das transcrições das falas, subentende-se que as acadêmicas das duas universidades gostariam de um estudo mais aprofundado: “[...] apenas uma disciplina” (Larissa, UNESP, 2017); "[...] foi abordado, mas infelizmente, em apenas um momento do curso, logo no começo" (Mônica, UNESP, 2017).

Acho que nós tivemos pouca preparação na licenciatura para casos diferentes de alunos. $\mathrm{Na}$ licenciatura não abordamos nada, basicamente isso. [...] no mestrado, [...] esses conteúdos não são, não são aprofundados, [...] pra além do mais acho que coisas práticas, como essa, como abordar uma criança, como identifica-la, como... não é explorado. Não é explorado e isso é muito mau para nós (Manuela, UMinho, 2017).

Quando questionadas sobre um autor de referência na área cujos textos/teorias foram lidos ou citados durante as aulas, uma das estudantes da UNESP mencionou Joseph Renzulli, enquanto todas as demais não souberam responder.

Cabe evidenciar que o Professor A não ministra disciplinas nos cursos de formação docente, pois se dedica especialmente, ao programa de doutoramento.

Outras fontes de informação

Além do contato com a área proporcionado pelos estudos das disciplinas que se propõem a abordar o tema, a aquisição de conhecimentos também ocorre na participação ou proximidade com os participantes de projetos de pesquisa/extensão:

"Eu não... nunca conheci uma criança, mas pelo relato das pessoas que trabalham no projeto da UNESP, do próprio professor, eu me lembro que [...]” (Mônica, UNESP, 2017). UNESP, 2017).

"O que eu sei é porque uma amiga minha participava da equipe [do PAPCS]". (Larissa,

Questionamos a estudante Larissa a respeito das possibilidades e pré-requisitos para a participação no PAPCS e esta evidenciou desconhecer o processo de ingresso na equipe: "Eu não sei. Sei que ela [a amiga] desenvolvia o projeto de IC [Iniciação Científica] e o TCC [Trabalho de Conclusão de Curso] com essa temática e orientada pelo [Professor B]" (Larissa, UNESP, 2017). de conhecimentos:

Semelhantemente, os eventos de natureza científica também contribuem para a apropriação

No mestrado foi mesmo superficial, acho que foi mais assistir também a conferências também a falar um pouco sobre isso, já participei em workshops recentes, estavam relacionados com a criatividade e as pessoas abordavam também um pouco em níveis de criatividade e falavam um pouco sobre sobredotação e foi mais por aí, um apanhado disso tudo. (Manuela, UMinho, 2017).

Em uma investigação envolvendo 44 professores de $1^{\circ}$ ciclo no concelho de Beja, Portugal, apenas quatro afirmaram possuir alguma formação na área da sobredotação. Seus conhecimentos foram adquiridos por meio de seminários, palestras ou colóquios, o que demonstra a contribuição dos eventos científicos para a formação docente (LANÇA, 2014).

Os professores são de suma importância para a identificação das AH/SD e promoção de atividades pedagógicas que incentivem o desenvolvimento das potencialidades e interesses dos estudantes (GUENTHER, 2012). Entretanto, precisam estar sensibilizados e de posse dos conhecimentos que lhes permitam observar e registrar os indicadores de AH/SD apresentados, bem como planejar e conduzir a execução das atividades que estimulem e potencializem esse diferencial (LANÇA, 2014). Assim sendo, essa temática não pode estar ausente dos cursos de formação inicial de professores e seu estudo deve contemplar, em profundidade suficiente, fundamentação teórica, características mais comuns, os 
processos e identificação e avaliação das AH/SD e estratégias de atendimento educacional, porém, muitos cursos ignoram a relevância desses conhecimentos na formação dos futuros professores (MARTINS; CHACON; ALMEIDA, 2018; MARTINS; CHACON, 2017).

\section{b) Conhecimentos adquiridos}

Parte da entrevista destinou-se à coleta de informações referentes aos conhecimentos dos formandos e recém-formados a respeito das AH/SD. A categoria Conbecimentos adquiridos abrange as subcategorias: (iii) Concepção de altas habilidades/superdotação; (iv) Características de estudantes com altas habilidades/superdotação; e (v) Processo de identificação.

Concepção de altas habilidades/superdotação

A maneira de se conceber as AH/SD depende do referencial teórico adotado. Para as estudantes da UNESP, a presença de habilidade(s) elevada(s) é um fator marcante:

"Penso que é como um talento, a pessoa já nasce com ele, uma habilidade muito forte em alguma coisa [...]” (Juliana, UNESP, 2017). “[...] apresentam habilidades acima, um desempenho notável acima da média em determinada inteligência, [...] não quer dizer que a pessoa ela tem uma inteligência acima da média em todas as áreas do conhecimento". (Mônica, UNESP, 2017). "São crianças que têm habilidades gerais ou específicas acima da média [...] o modo como ela se envolve com as tarefas e sua criatividade" (Larissa, UNESP, 2017).

Observa-se que as concepções de AH/SD apresentadas são influenciadas pela teoria dos três anéis de Renzulli (1978), que compreende esse fenômeno como um resultado da interação entre habilidade acima da média, criatividade e comprometimento com a tarefa. $\mathrm{O}$ autor esclarece que os três anéis precisam estar presentes, porém, não em mesma proporção, pois ocorre uma compensação entre eles. Contudo, parece haver uma maior valorização das habilidades destacadas por parte das estudantes.

A estudante Juliana (UNESP) destaca o componente genético ao conceituar a superdotação. Observa-se que não é raro encontrar pessoas com AH/SD que possuem parentes diretos de até terceira geração com tais características, entretanto, é um erro atribuir esse fenômeno exclusivamente à herança genética, pois esta, sem as condições ambientais que permitam o desenvolvimento do potencial, não garante o surgimento da habilidade, bem como um ambiente favorável e estimulante, por si só, não é suficiente. É necessário que haja a interação entre os aspectos biológicos e ambientais para que as AH/SD se manifestem (PÉREZ, 2003; WINNER, 1998).

Entre as acadêmicas da UMinho, percebe-se uma forte associação entre as AH/SD e os testes de QI nas respostas de duas entrevistadas, marcando assim, uma concepção mais tradicional.

A sobredotação pra mim [...] pode ser demonstrada em várias áreas. [...] é quando o aluno revela capacidades superiores a sua normalidade. [...] acho que tem um bocado relação com a criatividade, não sei se estou em erro, mas acho que também entra um pouco a criatividade. [...] Acho que sobredotado está ali um bocado no gênio. [...] também tem muito haver com o QI também acho eu, também acho que entra aí o QI (Manuela, UMinho, 2017).

"Penso que são crianças que a nível cognitivo são... tem, sobretudo, tudo a ver com o QI, penso, com o nível de inteligência, não é? Que é mais elevado. Penso que seja isso" (Carmen, UMinho, 2017).

As pontuações em testes de QI não garantem a presença de $\mathrm{AH} / \mathrm{SD}$, bem como não identificam potencial para desenvolver habilidades (GUIMARÃES; OUROFINO, 2007). Para López Garzón (2012), o estabelecimento de um ponto de corte para determinar se um estudante tem AH/SD ou não, é visto como uma questão de arbitrariedade que pode resultar em falsos negativos, isto é, a não identificação de estudantes que de fato apresentam AH/SD. Desse modo, aconselha a adoção de concepções as mais amplas possíveis.

A associação de criança com AH/SD e genialidade também denota desconhecimento, pois o gênio é aquele que cujas qualidades excepcionais permitiram prestar contribuições de extraordinário reconhecimento social dentro de sua área de conhecimento, ou seja, constituem casos verdadeiramente raros (CUPERTINO, 2008; LÓPEZ GARZÓN, 2012). 
Já a estudante Sílvia (UMinho) enfatiza a presença de habilidade acima da média, tal como ocorreu com as estudantes da UNESP: "É uma criança que tem competências de um nível acima das restantes, do que considerado o normal pra aquela faixa".

Características de estudantes com altas habilidades/superdotação

Ao relatarem as características que associam às crianças com $\mathrm{AH} / \mathrm{SD}$, as estudantes mencionam indicadores que condizem com a literatura, porém, também demonstram algumas ideias equivocadas.

"[...] geralmente tem muita dificuldade de se relacionar com os outros, por vezes até por terem pensamentos muito diferentes. São sérios. Perfeccionistas naquilo que são melhores" (Juliana, UNESP, 2017). "Criatividade, energia, mais interesse na área onde tem mais habilidade e menos nas que tem menos" (Larissa, UNESP, 2017).

[...] são crianças rebeldes e com mau comportamento em sala ou que não gostam de ir pra sala, não gostam de ir pra escola ou às vezes tímidas demais, não conseguem se relacionar com os outros, fazer amizade, estabelecer esse vínculo. Me lembro também que... Tem crianças que apresentam vocabulário muito avançado pra sua idade, tem dificuldade com rotina, mas também esse lado comportamental às vezes agressivo né? de não gostar de ir pra escola e preferir às vezes trabalhar sozinho, né? Justamente porque não conseguir se relacionar com os colegas. (Mônica, UNESP, 2017).

Curiosa [...]. Um pouco ambiciosa também. Gosta daquilo que faz, [...] é obcecada por aquela área. Não obcecada no sentido negativo, mas, um pouco essa parte do gênio e também, como referi, é uma criança que não impõe limites ao conhecimento também. Gosta de saber mais, mais, quer mais. É sedenta de conhecimento, quer aprender mais e mais (Manuela, UMinho, 2017).

"Não sei, [...] devem acabar por se isolar mais porque de certo não se sentem que estás integrado num grupo com a mesma faixa etária e estando elas com uma capacidade mais elevada talvez acabam por se sentir sozinhos ou por sentir inferiores, talvez" (Carmen, UMinho, 2017). "Ora bem, imagino uma criança que mostra resultados, mais resultados que as restantes, agora pode ser tímida ou não, isso depende da personalidade" (Sílvia, UMinho, 2017).

Crianças com AH/SD tendem a apresentar amplo vocabulário, interesses diversos aos de seus pares etários, curiosidade, criatividade, alto índice de energia, motivação e perfeccionismo, porém, não se pode traçar um perfil estático de personalidade, como bem pontua a estudante Sílvia (UMinho) (ALMEIDA; OLIVEIRA, 2010; MARTINS; CHACON, 2016; OUROFINO, 2007; PANZERI, 2006; PÉREZ, 2009; SABATELLA, 2012; VIRGOLIM, 2007). Existem aquelas que são sérias e pouco sociáveis, como também as que são desinibidas e populares. Algumas apresentarão comportamentos inapropriados enquanto outras serão consideradas como alunos excelentes. O fato de gostar ou não gostar da escola dependerá dos desafios e estímulos que encontrará no ambiente educacional (MARTINS; CHACON, 2016). De acordo com Pérez (2003), a desinformação leva muitas pessoas a relacionarem as $\mathrm{AH} / \mathrm{SD}$ a certas características físicas e desvios ou transtornos psicológicos e/ou de personalidade quando esses aspectos podem acometer o indivíduo com superdotação na mesma proporcionalidade em que se faz presente no restante da população.

Nas falas dos dois grupos de estudantes emergem equívocos. Como os mitos são um dos assuntos tratados no curso de Pedagogia da UNESP, é provável que no decorrer do trabalho de desmitificação de imagens estereotipadas, as quais relacionam as AH/SD a alunos com ótimas notas, bom comportamento e isolamento (PÉREZ, 2003), alguns estudantes acabem por traçar um perfil inverso daquele que é apresentado como incorreto. Entre as acadêmicas da UMinho, possivelmente, trata-se de um reflexo do destaque dado a outras necessidades educacionais especiais em detrimento da temática da sobredotação.

Processo de identificação

As opiniões expressas pelas estudantes evidenciam, de um modo geral, o reconhecimento da importância do professor no processo de identificação. 
O papel do professor é fundamental nessa situação para encaminhar essa criança para grupos de atendimento específico a isso. [...] O [Professor B] explicou sobre o projeto [...]. Acho que observa-se a criança no todo considerando as múltiplas inteligências. Como ela se relaciona, como ela se comunica. Leva-se em consideração também informações da escola, mas aplica-se atividades, testes, acho que diversas áreas (Mônica, UNESP, 2017).

"Primeiramente através da observação do professor, e depois encaminhadas a especialistas que com o tempo confirmará ou não as altas habilidades/superdotação, mas não devem ser rotuladas" (Larissa, UNESP, 2017).

Assim, pelas metas e por aquilo que temos enquanto educadores [...]. Estar atento a essas aprendizagens que estão nas metas e ver que realmente pra aquela criança aquilo que está naquelas metas [...] já é fácil. Penso que é sobretudo pela atenção que os educadores e que as pessoas têm, não é? E com as competências que sabem pela idade, pronto, deve estar e ver que realmente estas crianças de certo estão mais... estão além dessas capacidades (Carmen, UMinho, 2017).

Ora bem, eu acho que à partida elas devem sobressair relativamente às restantes não é? À partida o professor deve ter alguma ideia de que aquela criança estará num nível mais superior, mesmo através de teste assim saberá. Testes em termos de: ela faz o mesmo que as restantes, certo? E à partida o professor deve ter uma ideia de que a criança está bastante acima do que suposto para a faixa etária (Sílvia, UMinho, 2017).

Nos excertos anteriores, nota-se que as estudantes da UNESP percebem o professor como o profissional que identifica os primeiros sinais e faz o encaminhamento aos especialistas para que os indicadores sejam confirmados ou não. Entre as estudantes da UMinho, o professor é visto como o principal (ou único) responsável por essa identificação. Essa diferença de concepção pode estar relacionada ao fato de que a UNESP de Marília tem um programa de atenção que recebe estudantes encaminhados pelas escolas, além dos que chegam por demanda espontânea (CHACON; MARTINS; PEDRO, 2017).

Os trechos a seguir expressam incertezas a respeito do processo de identificação:

"Acho que quando percebemos que a criança tem muita facilidade, sabe falar sobre assuntos que não são muito comuns, são bem fechados também. Agora quem diz se é ou não é... não sei te responder" (Juliana, UNESP, 2017).

Não sei, não sei como é que as pessoas conseguem... [...] Pois eu acho que deviam reencaminhar [...]. Deve haver pessoas nesse âmbito, certo? A trabalhar com a sobredotação. Há certamente, há investigadores nesse campo, há pesquisas, portanto, acho que ela devia ser reencaminhada para um profissional em questão, não é? Fazer os testes. (Manuela, UMinho, 2017).

Segundo Cupertino (2008), somos todos capazes de identificar pessoas com habilidades superiores a partir da observação cotidiana direta, porém, perante a valorização social das medidas exatas, esse tipo de identificação perde sua credibilidade. Assim, recomenda-se o entrecruzamento de diversas opiniões a propósito da mesma pessoa: o professor, a família, os colegas de classe, outros professores que já tiveram contato com o educando que apresenta os indicadores observados, e até mesmo o próprio estudante, devem participar do processo. Soma-se a coleta de opiniões às avaliações de desempenho, escalas de características, questionários e observação direta do comportamento. Instrumentos padronizados de avaliação de habilidades e criatividade também podem integrar o processo (NAKANO; WECHSLER, 2006).

No estudo conduzido por Lança (2014), a maioria dos 44 professores participantes revelou não conhecer as necessidades educacionais desse público (37), as estratégias pedagógicas indicadas (38), tampouco as modalidades de intervenção previstas na legislação (39). O desconhecimento dos profissionais da área da educação a respeito desse tema ocasiona a invisibilidade dos estudantes que possuem capacidades superiores à média e necessitam de desafios e estímulos para que se desenvolvam continuamente.

Em estudo realizado pela Eurydice (2008), com o intuito de analisar as políticas educacionais de 30 países da Europa em relação às ações de promoção das AH/SD, concluiu-se que cerca de metade dos países investigados tem as altas habilidades/superdotação como um componente curricular 
obrigatório, ao passo que outros 10 não dispõem de qualquer recomendação legal a esse respeito. Com relação à abordagem adotada, a maioria dos países prefere integrar o tema a disciplinas mais abrangentes, como as destinadas às necessidades educativas especiais ou psicologias. Alemanha, Letônia, Áustria e Eslováquia ministram o conteúdo em disciplinas autônomas, enquanto que Grécia e Eslovénia tratam a questão tanto em módulos específicos quanto em tópicos de disciplinas mais amplas.

Brasil e Portugal não são países onde existe a obrigatoriedade de abordar às $\mathrm{AH} / \mathrm{SD}$ nos currículos de formação docente, mesmo assim, os cursos analisados optam pelo tratamento da questão e o fazem, principalmente, como tópico de disciplina mais abrangente. Barreto e Mettrau (2011) salientam a premência da inclusão de disciplinas que abordem as AH/SD nos cursos de formação de professores a fim de qualificá-los para reconhecer, indicar e atender educacionalmente, esses discentes.

\section{Os projetos de pesquisa e extensão na formação de professores}

Considerando-se que a universidade deve sustentar-se na necessária indissociabilidade entre Ensino, Pesquisa e Extensão (GONÇALVES, 2015), convém analisar as implicações dos projetos de pesquisa e extensão relacionados às $\mathrm{AH} / \mathrm{SD}$ na formação de professores. A análise de conteúdo do material coletado resultou na identificação de duas categorias: (c) Contribuições teóricas e (d) Contribuições práticas.

\section{c) Contribuições teóricas:}

O Professor A mantém desde 1992, um projeto de investigação denominado "Variáveis contextuais e pessoais do desenvolvimento, aprendizagem e desempenho", o qual corresponde a um projeto amplo que congrega várias temáticas, entre elas a superdotação e a excelência ${ }^{6}$. Este projeto originou o Grupo de Investigação Cognição, Aprendizagem e Desempenho (GICAD), que conta com a participação de estudantes de mestrado, doutorado e pós-doutorado, reunindo pesquisadores portugueses e do exterior. Como contribuições teóricas na área das AH/SD, o professor se recorda de ter orientado ou coorientado nove teses de doutorado e várias dissertações de mestrado, uma delas na Universidade Pedagógica de Moçambique, representando a estreia do assunto na produção acadêmica daquele país. Também foram muitos os artigos científicos derivados deste projeto.

Agora, em termos de artigos, de fato foi produzido muito artigo, mas, quer dizer, artigos em revistas nacionais e internacionais, houve artigos publicados em volumes de atas porque depois me envolvi na ANEIS e a ANEIS tem um congresso que tem atas e também tem uma revista, que é a Revista Sobredotação, portanto, é mais difícil quantificar o número de artigos publicados com estas pessoas porque geralmente, cada tese dá origem a dois, três artigos com essas colegas, não é? (Professor A, UMinho, 2017).

No período de 2003 a 2009, desenvolveu o projeto de pesquisa "Sobredotação e excelência: fatores pessoais e de contexto", que além da participação de estudantes, teve a colaboração internacional de uma pesquisadora brasileira. Esse projeto ainda gera frutos em termos de publicação: "há dois anos, 2015, publiquei com a Solange Wechsler, um artigo na revista Estudos de Psicologia sobre esse tema. [...] eu diria que esse interesse pela excelência permanece. Talvez mais forte agora do que pegar em idades [menores], compreendes?”.

Atualmente, desenvolve um projeto em parceria com a Universidade de Albacete, na Espanha, investigando as estratégias utilizadas por estudantes com AH/SD na área da matemática na resolução de problemas.

Vale frisar que o mestrado integra a formação inicial de professores em Portugal em decorrência do processo de Bolonha. Nesse sentido, os projetos de investigação da UMinho contribuem diretamente para a formação de alguns futuros professores no tema das $\mathrm{AH} / \mathrm{SD}$, ou seja, aqueles que escolhem desenvolver sua dissertação nesse campo.

Na UNESP, desde 2009, o Professor B desenvolve um projeto de pesquisa e extensão que, atualmente, chama-se Programa de Atenção ao estudante Precoce com Comportamentos de

\footnotetext{
${ }^{6}$ A excelência pode ser compreendida como a superdotação na vida adulta.
} 
Superdotação (PAPCS), mas que iniciou suas atividades com a denominação de Programa de atenção aos alunos superdotados e gênios (PROGEN) ${ }^{7}$, posteriormente nomeado como Programa de Atenção ao aluno Precoce com indicadores de Altas habilidades/superdotação (PAPAHS). As alterações de nomenclatura ocorreram em razão do aprofundamento teórico e aproximação à terminologia usada por Joseph Renzulli, referencial que embasa as ações deste projeto de investigação e intervenção. Em relação as suas contribuições teóricas, os estudos realizados resultaram na publicação artigos em periódicos e anais de eventos científicos, capítulos de livros, dissertações e teses.

Eu nem sei te dizer quanto que já tem de publicação [...] mas já tem bastante, bastante artigo. Olha, tem artigo publicado no Brasil, na Argentina, em Buenos Aires, em Paris, é... aí em Portugal, na Revista do Conbrasd, na Revista Brasileira de Educação Especial, na Revista de Educação Especial e tem capítulos de livro. Tudo fruto do programa. [...] são quatro dissertações e duas teses, por enquanto (Professor B, UNESP, 2017).

Enquanto projeto de pesquisa, tem a participação de estudantes de graduação que são bolsistas de Iniciação Científica e do Programa de Excelência Acadêmica (PROEX), além de orientandos de mestrado e doutorado.

Román Sánchez, Gallego Rico e Alonso (1996) destacam a influência das teses de doutorado na área da superdotação, as quais não formam professores diretamente, mas investigam o fenômeno a partir de várias dimensões e perspectivas, tendo impacto no estabelecimento de critérios, construção de instrumentos, programa de atenção e estratégias educacionais, entre outros. Essas pesquisas acabam por contribuir, indiretamente, para a formação dos professores e outros profissionais que atuam de maneira direta com a criança superdotada. Sob esse prisma, compreende-se que os artigos científicos, livros e capítulos também exercem essa mesma função.

\section{d) Contribuições práticas}

O Professor A (UMinho) tem participado de ações de âmbito nacional e internacional. Esteve envolvido na criação de um modelo de sinalização da superdotação a ser usado pela ANEIS a fim de que a identificação fosse coerente nas diversas regiões portuguesas. Trabalhou na publicação de um referencial nacional de avaliação para a entrada antecipada de crianças precoces na escola. Foi consultor e formador na Região Autônoma da Madeira, pioneira no estabelecimento de leis e programas de atenção a criança com $\mathrm{AH} / \mathrm{SD}$.

Mais uma vez tentamos definir qual era o guião que os psicólogos e os professores usavam, quais eram os instrumentos, as grelhas, as fichas e os testes que deveriam usar para sinalizar e também depois trabalhávamos com os professores a acompanhar. Lá a educação especial, na Madeira, desde o início sempre trabalhou com as crianças com dificuldade, com deficiência e a criança com sobredotação (Professor A, UMinho, 2017).

Desde 2006, tem participado de projetos de pesquisa ligados ao grupo de investigação "Altas Habilidades" da Universidade da Murcia, na Espanha. Este grupo atua na localização e validação de instrumentos internacionais que são usados na identificação de alunos com AH/SD, além de prestar apoio a professores na implementação de programas de enriquecimento. Os participantes são estudantes, investigadores e professores da educação básica, havendo ainda, a realização de congressos que contam com a presença de pessoas da comunidade externa à universidade. Todas essas importantes contribuições práticas à área das $\mathrm{AH} / \mathrm{SD}$ não envolvem, diretamente, os estudantes dos cursos de formação inicial de professores.

O Professor B (UNESP) foi chamado, em 2008, para avaliar um aluno que apresentava comportamentos avançados para sua idade, o qual foi identificado como precoce e passou a ser levado para a UNESP, tendo início um trabalho de enriquecimento com essa criança, realizado de maneira informal. No ano seguinte, outras crianças foram identificadas e o programa institucional de atenção a esses estudantes surgiu de fato. Atualmente denominado como PAPCS, beneficia a comunidade por meio da oferta de cursos de capacitação a professores, do oferecimento de oficinas para famílias e de

\footnotetext{
${ }^{7}$ Esse programa foi idealizado com a participação de Carlos Eduardo Paulino, na época, aluno do curso de graduação em Pedagogia.
} 
enriquecimento aos alunos com precocidade ou comportamentos de superdotação. O Professor B ressalta a importância do trabalho desenvolvido com os pais dos alunos participantes, o que considera ser um diferencial do programa.

Além dos orientandos de graduação e pós-graduação, a equipe do programa também conta com a participação de voluntários.

"A Bia participou durante muito tempo e atualmente nós temos o Alex [...]. Ele participa como voluntário também. E tem algumas participações esporádicas de pessoas que vêm dar um curso de inglês, uma oficina de estêncil, e isso são participações voluntárias" (Professor B, UNESP, 2017).

O Professor B desenvolveu uma parceria com a Diretoria de Ensino do Estado de São Paulo, região de Marília, para a realização de um processo de identificação e avaliação em uma escola com 300 alunos matriculados, o qual resultou em 23 crianças/adolescentes com seus indicadores de AH/SD confirmados. Também iniciou uma parceria com a Secretaria Municipal de Educação de Marília para assessorar o município na identificação, avaliação e elaboração de um programa de atenção aos alunos com habilidades que ultrapassam a média.

O Professor B acredita que também está contribuindo para uma maior objetividade dos processos de identificação e avaliação:

[...] quando a gente vai para os congressos, participar e mostrar o trabalho, nós temos um método que a gente utiliza testes validados, né? Instrumentos validados. [...] a maioria das pessoas não sabe usar esses instrumentos, [...] então ficam [criticando], mas quando vê, quando trabalha com o instrumento e vê o resultado, aí vê a diferença (Professor B, UNESP, 2017).

Essa perspectiva psicométrica tem sido reforçada pelos pesquisadores do campus de Bauru da Unesp, com quem o Professor B desenvolve um trabalho de colaboração, participando de bancas de mestrado e doutorado, além de oferecer uma disciplina.

Bauru começou um trabalho bom de altas habilidades por conta do nosso trabalho [...]. Eles nem trabalhavam com precoce, agora estão trabalhando também. [...] as bancas de mestrado e doutorado que saem do projeto deles, normalmente eu participo [...], assim como quando eles vêm participar das nossas bancas, eles também, indiretamente, estão avaliando o nosso trabalho, né? [...] inclusive, a última disciplina que eu ofereci de superdotação, nós tivemos dois alunos matriculados aqui de Marília e seis alunos matriculados de Bauru. A disciplina era oferecida presencial para os dois daqui e em vídeo conferência para os seis de Bauru (Professor B, UNESP, 2017).

Os estudantes em formação inicial na UNESP têm a possibilidade de participar do PAPCS, embora essa oportunidade possa não ser do conhecimento deles, como visto anteriormente. Além desta rica vivência direta, os estudantes também podem se beneficiar das demais contribuições práticas do Professor B indiretamente, a partir dos relatos do docente nas disciplinas que oferece. Já os estudantes da UMinho, pouco podem usufruir dos saberes e da experiência do Professor A neste campo, pois o mesmo não atua na formação de professores, exceto na orientação de teses de mestrado, porém, diante da superficialidade com que o tema é tratado no âmbito das disciplinas curriculares, as chances de escolha deste assunto para investigação são reduzidas.

\section{A disponibilidade de acesso ao conhecimento por meio de produçôes científicas}

É passado o tempo em que as bibliotecas eram os principais espaços destinados à pesquisa. Com a ascensão das tecnologias de informação e comunicação, as bibliotecas perderam a primazia, porém, não a sua importância no processo de aquisição de conhecimentos. Dada à concepção de que o estudante deve ocupar o papel central em seu processo formativo (PORTUGAL, 2005), destaca-se a relevância da pesquisa, a qual depende do acesso a produções científicas atuais e de importância para o avanço do conhecimento de uma determinada área. Sendo assim, buscamos conhecer e analisar o que as universidades participantes do estudo oferecem ao corpo discente em termos de materiais físicos ou digitais para pesquisa científica no referente às $\mathrm{AH} / \mathrm{SD}$, em seu acervo. As produções científicas disponíveis nas universidades analisadas são apresentadas na Tabela 1: 
Tabela 1 - Distribuição das produções científicas disponíveis na UMinho, Campus de Gualtar e na UNESP, Campus de Marília.

\begin{tabular}{l|c|c}
\hline \multicolumn{1}{c|}{ Tipo de produção } & UMinho-Gualtar & UNESP-Marília \\
\hline Livros & 30 & 18 \\
Capítulos de livros & 02 & 02 \\
Teses & 04 & 02 \\
Dissertações & 04 & 04 \\
Trabalhos de Conclusão de Curso & 0 & 02 \\
Números de periódicos específicos & 20 & 0 \\
Artigos publicados em periódicos & 19 & 10 \\
Artigos publicados em anais de eventos científicos & 06 & 03 \\
Resumos publicados em anais de eventos & 01 & 0 \\
científicos & & \\
Outros & 01 & 01 \\
\hline Total & 87 & 42 \\
\hline
\end{tabular}

Fonte: Elaboração própria.

Com base nas informações sistematizadas na Tabela 1, observa-se que o acervo bibliográfico da UMinho (Campus de Gualtar) é consideravelmente maior que o acervo da UNESP (Campus de Marília). Há uma quantia de livros mais expressiva por parte da UMinho, que também possui uma coleção impressa da revista Sobredotação. A UMinho também apresenta maior disponibilização de artigos publicados em periódicos e anais de eventos científicos.

Essas unidades universitárias apresentam equivalência em relação à produção de trabalhos acadêmicos na área, de modo que foram orientados quatro dissertações de mestrado e quatro teses de doutorado na UMinho (Campus de Gualtar) e, dois Trabalhos de Conclusão de Curso (TCC), quatro dissertações de mestrado e duas teses de doutorado na UNESP (Campus de Marília). A Tabela 2 apresenta a distribuição das produções disponíveis segundo o período de publicação:

Tabela 2: Distribuição das produções conforme o período de publicação

\begin{tabular}{c|c|c}
\hline Período & UMinho-Gualtar & UNESP-Marília \\
\hline $1900-1949$ & 1 & 1 \\
$1950-1959$ & 0 & 3 \\
$1960-1969$ & 0 & 1 \\
$1970-1979$ & 0 & 1 \\
$1980-1984$ & 1 & 0 \\
$1985-1989$ & 3 & 0 \\
$1990-1994$ & 5 & 1 \\
$1995-1999$ & 13 & 2 \\
$2000-2004$ & 18 & 2 \\
$2005-2009$ & 13 & 6 \\
$2010-2014$ & 24 & 16 \\
$2015-2017$ & 9 & 9 \\
\hline Total & 87 & 42 \\
\hline
\end{tabular}

Fonte: Elaboração própria.

Ao analisarmos a Tabela 2, percebe-se que ambas as unidades possuem pouco material bibliográfico publicado anteriormente a 1990. A partir desse período, a UMinho (Campus de Gualtar) começou a adquirir/produzir materiais bibliográficos progressivamente, enquanto que a UNESP (Campus de Marília) apresentou um acervo tímido até o período de 2005 a 2009, quando passou a demonstrar uma aquisição/produção considerável. Tanto a UNESP (Campus de Marília) quanto a UMinho (Campus de Gualtar) tiveram o período de 2010 a 2014 como o mais expressivo, bem como apresentaram equivalência em termos dos materiais disponibilizados com publicação no biênio 2015$2017^{8}$. Percebe-se que a presença intensiva dessas produções nos campi tem correlação com o início do interesse dos professores A e B pela temática das AH/SD. O Professor A, que está envolvido com a área

${ }^{8}$ O segundo semestre do ano de 2017 não foi considerado porque o levantamento ocorreu em julho deste ano. 
desde 1987, ingressou na UMinho ao final do ano de 1988. Ao passo que o Professor B, tem o interesse despertado em 2008/2009. Aliás, infere-se que as primeiras solicitações de aquisição de livros se referiram a publicações que antecederam a essas datas de referência, o que explica a presença de algumas produções nos intervalos de tempo imediatamente anteriores às datas que marcam o princípio da dedicação dos docentes ao tema em seus respectivos campi.

Diante desta análise, compreende-se que a presença de professores interessados no desenvolvimento de estudos e pesquisas sobre as AH/SD nas universidades, influencia a disponibilidade de acesso ao conhecimento para professores em formação, por intermédio das produções científicas. Nessa perspectiva, o fato de possuir um docente envolvido com a área desde 1988, justifica a maior aquisição/produção de materiais bibliográficos por parte da UMinho (Campus de Gualtar).

Segundo Hübner e Andretta (2016), a competência e a independência dos usuários das bibliotecas universitárias para localizar e selecionar informações, no presente, representam um desafio a esses setores que percebem a gradativa diminuição de seu público. Sendo assim, os autores realizaram uma pesquisa sobre a relação entre o sucesso acadêmico e a utilização dos serviços da biblioteca universitária. A partir da análise das médias acadêmicas de 262 estudantes, graduados em nove cursos diferentes no período de 2005 a 2012, e do número de material bibliográfico retirado para leitura em domićlio, concluiu-se que quanto maior é o uso dos serviços da biblioteca, maiores são os conceitos finais atingidos pelos estudantes. Ao entrevistarem o estudante com maior desempenho acadêmico em cada uma das turmas, verificaram que os acadêmicos atribuíam grande importância aos materiais disponibilizados para a aprendizagem e o êxito adquiridos.

Grande parte dos materiais disponibilizados pelas universidades investigadas encontra-se em formato digital. Considerando a propagação e o desenvolvimento contínuos das infraestruturas tecnológicas nas universidades. Mora, Santos e Chico (2017) investigaram os fatores que incentivam o uso da biblioteca virtual por parte dos universitários. Os autores encontraram que a facilidade de uso e a percepção de utilidade, esta impactada pelo incentivo dos docentes, constituem os principais fatores que impulsionam o uso das bibliotecas virtuais.

Nesse sentido, a formação de professores acerca das AH/SD é favorecida quando existem possibilidades para adquirir conhecimentos por meio do acesso a livros, artigos, teses e dissertações. No entanto, não é suficiente disponibilizar um vasto acervo de produções científicas sobre AH/SD. É preciso que haja facilidade na localização dos materiais físicos ou digitais, bem como estímulos por parte dos professores.

\section{CONSIDERAÇÕES FINAIS}

Tendo por objetivo investigar e comparar a formação de professores na temática AH/SD no curso de Pedagogia da UNESP (Campus de Marília), Brasil, e na Licenciatura em Educação Básica e nos Mestrados em Ensino da Universidade do Minho (Campus de Gualtar), Portugal, investigamos os estudos realizados juntamente com as concepções de estudantes dessas universidades sobre a temática; analisamos a relação de projetos de pesquisa e extensão com a formação inicial de professores e verificamos o acervo de produções sobre $\mathrm{AH} / \mathrm{SD}$ disponibilizadas aos estudantes.

Os resultados mostram que cada um dos campi investigados possui um docente envolvido com as AH/SD. O Professor A (UMinho) dedica-se à orientação de pesquisas em nível de mestrado, doutorado e pós-doutorado. O Professor B (UNESP) orienta dissertações e teses, ministra disciplinas de graduação e desenvolve projetos de extensão. O envolvimento desses docentes com a temática exerce influências sobre a produção e aquisição de materiais bibliográficos aos discentes, tendo a UMinho, uma coleção significativamente mais expressiva, o que se justifica pelo tempo em que os docentes vêm se dedicando às AH/SD, uma vez que o Professor A iniciou esse contato na década de 1980 e o Professor $\mathrm{B}$, cerca de 20 anos depois.

Em relação ao currículo formal, não há qualquer referência à sobredotação durante o curso de Licenciatura em Educação Básica da UMinho (Campus de Gualtar). Embora tenha a temática como conteúdo de uma de suas disciplinas dos Mestrados em Ensino, esta é abordada superficialmente, pois se privilegia os estudos acerca das deficiências. Em contrapartida, a temática das AH/SD não consta 
explicitamente nos planos de ensino do curso de Pedagogia da UNESP, porém, o Professor B promove o estudo desta necessidade educacional em qualquer disciplina ministrada. Dessa maneira, nota-se que o estudo da temática relaciona-se mais com os projetos de pesquisa dos docentes que com os documentos que supostamente, orientam o ensino. Tal constatação parece-nos alarmante na medida em que as $\mathrm{AH} / \mathrm{SD}$ não podem estar ausentes dos conteúdos disciplinares que integram a formação de professores, do mesmo modo em que o desenvolvimento desse trabalho não pode ficar dependente do interesse científico de pesquisadores. Sem a formação dos professores nesta temática não é possível aumentar o número de crianças identificadas e atendidas pelos sistemas educativos, sendo a situação alarmante pela escassez de tais práticas (GARCIA-PERALES; ALMEIDA, 2019). Obviamente que a presença desses pesquisadores aumenta as possibilidades de novos conhecimentos e conhecimentos mais aprofundados sobre o assunto, mas é preciso garantir que todos os futuros professores entrem em contato com tais conhecimentos nos componentes curriculares de seus cursos. É, sobretudo, importante que possam adquirir as competências mínimas para identificarem e responderem às necessidades educacionais desses alunos nas suas práticas em sala de aula, e possam sobre estes temas dialogar com profissionais mais habilitados. Aliás, nos dois casos investigados, os estudantes expressaram a necessidade de maior presença e profundidade no tratamento deste assunto, bem como apresentaram algumas dúvidas e ideias equivocadas acerca das $\mathrm{AH} / \mathrm{SD}$, o que indica a relevância de se incluir a abordagem sistemática deste tema nos currículos.

Tanto o Professor A quanto o Professor B desenvolvem projetos de contribuição prática e teórica para as AH/SD. Esses projetos podem contar com a participação dos estudantes em formação inicial, possibilitando-lhes a ampliação dos conhecimentos, mas certamente, nem todos manifestam interesse por esse tipo de atividade, do mesmo modo em que podem desconhecer essa possibilidade, o que sugere a necessidade de maior divulgação e incentivo desse tipo de participação acadêmica. Mesmo assim, é de destacar a influência do PAPCS (UNESP) na aquisição de conhecimentos dos futuros professores, seja pela participação direta no programa ou pelo contato com os relatos dos colegas participantes e do próprio Professor B, quem o coordena. Os eventos científicos também podem promover informações relevantes aos acadêmicos, contudo, esse tipo de participação também tende a estar condicionado ao interesse do estudante.

O fato de restringir-se a análise de duas realidades isoladas é uma limitação deste estudo, a qual impossibilita o estabelecimento de quaisquer generalizações aos respectivos países. Como implicações para futuras pesquisas, o presente artigo alerta para a importância de se verificar a presença do tema $\mathrm{AH} / \mathrm{SD}$ nas disciplinas que compõem os programas de formação de professores não apenas a partir da análise documental, mas, inclusive, da investigação dos conhecimentos adquiridos pelos estudantes. Além da análise da estrutura curricular dos cursos, o levantamento de temas de Trabalhos de Conclusão de Curso ou experiências de estágio em escolas pode revelar outras maneiras de adquirir e/ou ampliar conhecimentos acerca da temática AH/SD.

\section{REFERÊNCIAS}

ALENCAR, E. M. L. S.; FLEITH, D. S. A atenção ao aluno que se destaca por um potencial superior. Cadernos de Educaşão Especial, Santa Maria, n. 27, p. 1-5, 2005.

ALMEIDA, L. S.; OLIVEIRA, E. Los alumnos con características de sobredotación: la situación actual en Portugal. REIFOP, v. 13, n. 32, p. 85-95, 2010.

ANTUNES, A. P.; ALMEIDA, L. S. Práticas educativas na sobredotação: diferenciação curricular e estratégias complementares. Psicologia Educação e Cultura, v. 13, n. 1, 157-168, 2009.

BARDIN, L. Análise de conteúdo. Tradução de Luís Antero Reto, Augusto Pinheiro. São Paulo: Edições 70, 2016. 
BAHIENSE, T. R. S.; ROSSETTI, C. B. Altas habilidades/superdotação no contexto escolar: percepções de professores e prática docente. Revista Brasileira de Educaşão Especial, v. 20, n. 2, p. 195-208, abr./jun. 2014.

BARRETO, C. M. P. F., METTRAU, M. B. Altas habilidades: uma questão escolar. Revista Brasileira de Educação Especial, Marília, v. 17, n. 3, p. 413-426, set./dez., 2011.

BRASIL. Resolução CNE/CP n. 1. Diretrizes Curriculares Nacionais para o Curso de Graduação em Pedagogia, Licenciatura. Diário Oficial da União, Brasília, DF: MEC, 2006.

BRASIL. LDB - Lei de Diretrizes e Bases da Educação Nacional: Lei no 9394, de 20 de dezembro de 1996, que estabelece as diretrizes e bases da educação nacional. Brasília: Presidência da República, 1996. Disponível em: http://www.planalto.gov.br/ccivil 03/leis/19394.htm. Acesso em: 13 out. 2019.

CARVALHO, R. E. Educaşão inclusiva: com os pingos nos “is". 11. ed. Porto Alegre: Mediação, 2016.

CASTELLÓ, A.; MARTINEZ, M. Alumnat excepcionalment dotat intel·lectualment: Identificació i intervenció educativa. Genaralitat de Catalunya: Departament d'Ensenyament, 1999.

CHACON, M. C. M.; MARTINS, B. A.; PEDRO, K. M. Programa de atenção a alunos precoces com comportamento de superdotação: enriquecimento e orientação para estudantes e familiares. In: Seminário Internacional "Cognição, Aprendizagem e Desempenho", V, 2017, Braga, PT. Atas do V Seminário Internacional "Cognição, Aprendizagem e Desempenho", Braga: UMinho, 2017, p. 1-13.

CUPERTINO, C. M. B. (Org.). Um olharpara as altas habilidades: construindo caminhos/Secretaria da Educação. São Paulo: FDE, 2008.

EURYDICE. Unidade Portuguesa. Educação de sobredotados na Europa. Lisboa: Gabinete de Estatística e Planejamento da Educação, 2008.

FLEITH, D. S. et al. Educação do aluno sobredotado no Brasil e em Portugal: uma análise comparativa. Revista Lusófona de Educação, n. 16, p. 75-88, 2010.

FORTES, C. C.; FREITAS, S. N. PIT - Programa de Incentivo ao Talento: um relato das experiências pedagógicas realizadas com alunos com características de altas habilidades. Revista Educação Especial, Santa Maria, v. 20, n. 29, jan./jun. 2007.

FREITAS, S. N.; STOBÄUS, C. D. Olhando as altas habilidades/superdotação sob as lentes dos estudos curriculares. Revista Educação Especial, Santa Maria, v. 24, n. 41, p. 483-500, set./dez. 2011.

GARCIA-PERALES, R.; ALMEIDA, L. S. (2019). Programa de enriquecimiento para alumnado con alta capacidad: Efectos positivos para el curriculum. Comunicar, v. XXVII, p. 39-48. DOI:10.3916/C60-2019-04

GONÇALVES, N. G. Indissociabilidade entre Ensino, Pesquisa e Extensão: um princípio necessário. PERSPECTIVA, Florianópolis, v. 33, n. 3, p. 1229-1256, set./dez. 2015.

GUENTHER, Z. C. Crianças dotadas e talentosas... Não as deixem esperar mais! Rio de Janeiro, LTC, 2012. 
GUimarães, T. G.; OUROFINO, V. T. A. T. Estratégias de identificação do aluno com altas habilidades/superdotação. In: FLEITH, D. S.(Org.). A construção de práticas educacionais para alunos com altas habilidades/superdotação. Brasília: Ministério da Educação, Secretaria de Educação Especial, 2007.

HÜBNER, M. L. F.; ANDRETTA, P. I. S. A relação entre sucesso acadêmico e biblioteca universitária: Uma análise a partir dos empréstimos domiciliares em uma universidade brasileira. Información, cultura y sociedade, n. 34, p. 45-62, jun. 2016.

IORO, N. M.; CHAVES, F. F.; ANACHE, A. A. Revisão de literatura sobre aspectos das avaliações para Altas Habilidades/Superdotação. Revista Educação Especial, Santa Maria, v. 29, n. 55, p. 413-428, mai./ago. 2016.

LANÇA, C. I. S. O. Conhecimentos e práticas de professores do $1^{\circ}$ ciclo no âmbito da educação de crianças sobredotadas. 2014. 123f. Dissertação (Mestrado em Educação Especial). Instituto Politécnico de Beja, Beja, Portuga, 2014.

LÓPEZ GARZÓN, J. C. Didáctica para alumnos com altas capacidades. Madrid: Editorial Sintesis, 2012.

MARTINS, A. C. S.; ALENCAR, E. S. Características desejáveis em professores de alunos com altas habilidades/superdotação. Revista Educação Especial. Santa Maria, v. 24, n. 39, p. 31-46, jan./abr. 2011.

MARTINS, B. A. A aceleração da criança precoce em idade pré-escolar. Revista diálogos e perspectivas em Educação Especial, v. 2, n. 2, p. 115-130, jul./dez. 2015.

MARTINS, B. A.; CHACON, M. C. M. Crianças precoces com indicadores de altas habilidades/superdotação: as características que contrariam a imagem de aluno "ideal". Educaşão Unisinos, v. 20, n. 1, p. 96-105, jan./abr. 2016.

MARTINS. B. A.; CHACON, M. C. M. Sobredotação e formação de professores: análise dos currículos dos cursos de Pedagogia da UNESP - Brasil. In: SEMINÁRIO INTERNACIONAL "COGNIÇÃO, APRENDIZAGEM E DESEMPENHO”, n. 5, 2017, Braga.

MARTINS, B. A.; CHACON, M. C. M.; ALMEIDA, L. S. Estudo comparativo luso-brasileiro sobre a formação inicial de professores em altas habilidades/superdotação com enfoque nos conteúdos curriculares. Revista Brasileira de Educação Especial, v. 24, n. 03, p. 309-326, jul./set. 2018.

MATOS, R. C. G. A formação dos docentes em sobredotação: a atual realidade da escola portuguesa. Lisboa: Escola Superior de Educação João de Deus, 2015. 154f. Dissertação (Mestrado em Ciências da Educação). Escola Superior de Educação João de Deus, Lisboa, Portugal, 2015.

MIRANDA, L.; ALMEIDA, L. S. Sinalização de alunos sobredotados e talentosos por professores e psicólogos: Dificuldades na convergência. Sobredotação, v. 04, n. 02, p. 91-103, 2003.

MORA, O. Y. C.; SANTOS, S. A. D.; CHICO, M. C. O. Factores que incentivan el uso de la biblioteca virtual en los estudiantes universitarios: un estudio de caso de la Universidad de Gómez Palacio de Durango. Biblios, n. 66, p. 98-111, 2017.

NAKANO, T. C.; WECHSLER, S. M. Teste brasileiro de criatividade figural: proposta de instrumento. Revista Interamericana de Psicologia, Porto Alegre, v. 40, n.1, p. 103-110, abr. 2006. 
OUROFINO, V. T. A. T. Altas habilidades e hiperatividade: a dupla excepcionalidade. In: FLEITH, D. S. Desenvolvimento de talentos e altas habilidades: orientação a pais e professores. Porto Alegre: Artmed, 2007, p. 51-66.

PANZERI, M. V. Los niños talentosos y superdotados una respuesta educativa: "enriquecimiento en la escuela común". In: FREITAS, S. N. (Orgs.). Educação e altas habilidades/superdotação: a ousadia de rever conceitos e práticas. Santa Maria: Ed. Da UFMS, 2006, p. 257-277.

PÉREZ, S. G. P. B. Mitos e crenças sobre as pessoas com altas habilidades: alguns aspectos que dificultam o seu atendimento. Cadernos de Educação Especial, Santa Maria, v.2, n.22, p. 45-59, 2003.

PÉREZ, S. G. P. B. A identificação das altas habilidades sob uma perspectiva multidimensional. Revista Educação Especial, Santa Maria, v. 22, n. 35, p. 299-328, 2009.

PÉREZ, S. G. P. B.; FREITAS, S. N. Encaminhamentos pedagógicos com alunos com Altas Habilidades/Superdotação na Educação Básica: o cenário brasileiro. Educar em Revista, Curitiba: UFPR, n. 41, p. 109-124, jul./set. 2011.

PORTER, L. Gifted young children: a guide for teachers and parents. 2. ed. Buckingham: Open University Press, 2005.

PORTUGAL. Ministério da Ciência, Inovação e Ensino Superior. Decreto-Lei $n^{0}$ 42/2005, de 22 de fevereiro, que institui os Princípios reguladores de instrumentos para a criação do espaço europeu de ensino superior, 2005.

PORTUGAL. Ministério da Educação. Decreto-Lei n $n^{\circ}$ 3/2008, de 7 de Janeiro. Diário da República no 4 I Série. Lisboa, 2008.

RENZULLI, J. S. What makes giftedness? Re-examining a definition. Phi Delta Kappa, [S.1.], v. 60, n. 3, p. 180-84, 261, nov. 1978.

RENZULLI, J. Modelo de enriquecimento para toda a escola: Um plano abrangente para o desenvolvimento de talentos e superdotação. Revista Educação Especial, v. 27, n. 50, p. 539-562, set./dez. 2014.

ROMÁN SÁNCHEZ, J. M.; GALLEGO RICO, S.; ALONSO, J. A. Preparación de profesores para alumnos superdotados. In: BENITO MATE, Y. (coord.). Desarrollo y educación de los niños superdotados. 2. ed. Salamanca: Amarú ediciones, 1996, p. 353-392.

SABATELLA, M. L. P. Expandir horizontes para compreender alunos superdotados. In: MOREIRA, L. C.; STOLTZ, T. (Orgs.). Altas habilidades/superdotação, talento, dotação e educação. Curitiba: Juruá, 2012, p. 113-128.

VIRGOLIM, A. M. R. Altas habilidades/superdotação: encorajando potenciais. Brasília: Ministério da Educação, Secretaria de Educação Especial, 2007.

WINNER, E. Crianças superdotadas: mitos e realidades. Porto Alegre: Artes Médicas, 1998. 
Submetido: $20 / 08 / 2018$

Aprovado: 11/10/2019

Contato:

Bárbara Amaral Martins

Av. Rio Branco, 1270, Universitário Corumbá | Mato Grosso do Sul (MS) | Brasil

CEP 79.304-902 